\title{
Exploration and Practice of the Training Mode of New Engineering Talents' Creative Practice Ability
}

\author{
Jianyong Li, Jianfeng Li", Zhaoliang Jiang, Zhenjie Zhu, Wenbo Bi \\ National Experimental Teaching Demonstration Center for Mechanical Foundation School of Mechanical Engineering, Shandong \\ University, Jinan 250061, China \\ Email: ljf@sdu.edu.cn
}

\begin{abstract}
Under the background of new engineering, according to the characteristics of engineering college students, we should cultivate high-level engineering talents with innovative practice ability to meet the needs of enterprises. Aiming at the problem of great investment and little effect in innovation practice teaching reform, this paper adheres to the principle of effectiveness, and combines the characteristics of college students, such as precocious thinking, active thinking, independent personality, impetuous self, eager for quick success and instant benefit, blind self-confidence, strong ability to take an examination. The status quo of serious lack of cognition and experience of engineering practice and its importance and the characteristics of intelligent manufacturing specialty. It is suitable for the cultivation of innovative practice ability of college students and the ways and measures to improve its effectiveness.
\end{abstract}

Keywords: new engineering, talents, innovative practice, ability, training mode

\section{Introduction}

In February 2017, a seminar on the development strategy of higher engineering education was held in Shanghai. The 30 key comprehensive universities and engineering colleges across the country reached the "Fudan Consensus" on the connotation, characteristics, construction and development path of the new discipline. Subsequently, the Ministry of Education issued the "Notice on the Development of New Engineering Research and Practice", which summarized the contents of the "New Engineering" construction into "Five New": the new concept of engineering education, the new structure of disciplines, and the new model of personnel training. The new quality of education and teaching, the new system of classification development, is a national-level strategy ${ }^{[1-2]}$. Therefore, talent training in the traditional equipment manufacturing industry urgently needs innovation transformation and innovation development. At present, the traditional teaching of engineering majors in colleges and universities has become more and more difficult to cope with the requirements of industry upgrading for talent innovation practice ability. Therefore, exploring the teaching of sustainable development of new engineering majors the concept and education model is imminent ${ }^{[3]}$.

Shandong University takes the first batch of new engineering specialty of "Intelligent Manufacturing Engineering" as the pilot, radiation mechanical engineering discipline, "Shandong University Machinery Foundation National Experimental Teaching Demonstration Center", "Shandong University Digital Design and Manufacturing National Virtual Simulation Experimental Teaching Center" "Shandong University-Shandong Lingong Group National Engineering Practice Education Center" and "Efficient Clean Machinery Manufacturing" Key Laboratory of the Ministry of Education, relying on the four teaching and research platforms, focusing on promoting high-quality innovative intelligent manufacturing new engineering talents practice Ability training. Constructing the "knowledge-design-practice-innovation" ability training and innovative practice teaching system to meet the requirements of the growth of new engineering talents, and carrying out the reform of the training program based on project traction, starting the graduation design from the sophomore, introducing engineering awareness in advance, and practicing teaching. The curriculum is the combination of knowledge, skills, and emotions of new engineering talents is realized. Establish a new engineering talents innovation practice ability training mode that combines teaching, practice, and scientific research, so that graduates have the historical mission and social responsibility to serve the national strategy, meet the industrial needs and face the future development, and obtain mechanical engineering, mathematics, materials science, etc. Basic knowledge of the discipline, with three cross-disciplinary (interdisciplinary, cross-school, cross-border learning) and four experiences (interdisciplinary/hospital learning experience, second campus learning experience, overseas learning experience and social practice experience), thus having the field of equipment manufacturing The original ability of innovation, industrial R\&D capability and entrepreneurial ability are three traits. The results have achieved the combination of production and education, science and education coordination, and 
competition and cooperation, and achieved remarkable results in cultivating the consistency of high-quality innovative new engineering talents ${ }^{[4-6]}$.

\section{The current problems}

(1) The discourse of theoretical classroom teaching and innovative practical ability education in the process of training new talents.

(2) The resource sharing of the experimental practice platform for new engineering talent training is poor, and there is an "island phenomenon".

(3) The evaluation mechanism for the cultivation of new engineering talents' innovation and practical ability needs to be improved and improved.

\section{The main measures of education reform}

(1) Build a "four-in-one" innovative practice teaching system that adapts to the training requirements of new engineering talents and "organic-design-practice-innovation", and develop a training system based on project traction, and advance the graduation design. At the beginning of the sophomore year, the engineering consciousness was introduced in advance, and the teaching was carried out to carry out the construction of the curriculum, so as to realize the organic combination of the knowledge, skills, and emotions of the new engineering talents.

Establish a clear professional training goal: facing the national intelligent manufacturing strategy, national and regional economic and social development needs, facing basic and applied basic research, transformative technology, strategic high technology, strategic emerging industries, facing "Chinese characteristics, world-class In order to meet the challenges of a new economy characterized by new technologies, new industries, new types of business and new models, we must adhere to the concept of "wide-caliber, thick foundation, strong practice, and good innovation" and comprehensively apply intelligence. Manufacturing theory, artificial intelligence, modern mechanical design methods and computer technology, cultivating the ability to develop and manufacture intelligent manufacturing technology and equipment, master a wide range of basic theories, solid professional knowledge and basic skills, with comprehensive innovation awareness, independent workability, teamwork spirit, a high sense of social responsibility, a good cultural literacy, a profound professional foundation, a broad international vision, and a high-quality innovative new engineering talent with a sound personality ${ }^{[7]}$.

Construct a scientific and rational new engineering talents practical ability training system: carry out the reform of the training program based on project traction, advance the graduation design to the sophomore year, introduce engineering awareness in advance, grasp the professional needs and professional teaching characteristics, and train the new engineering students ${ }^{[8-10]}$. The combination of basic theory courses, professional basic courses and professional courses, combining knowledge (basic theory, professional foundation and professional knowledge), design ( 3 course design, 1 graduation design), practice (engineering training, experiment, internship, social practice) (etc.) and innovation (innovative design, competition, etc.) ability training, the establishment of organic integration of "knowledge-design-practice-innovation" ability training and innovative practice teaching system. Practice teaching to carry out the construction of the curriculum, and realize the organic combination of the knowledge, skills, and emotions of new engineering talents. 


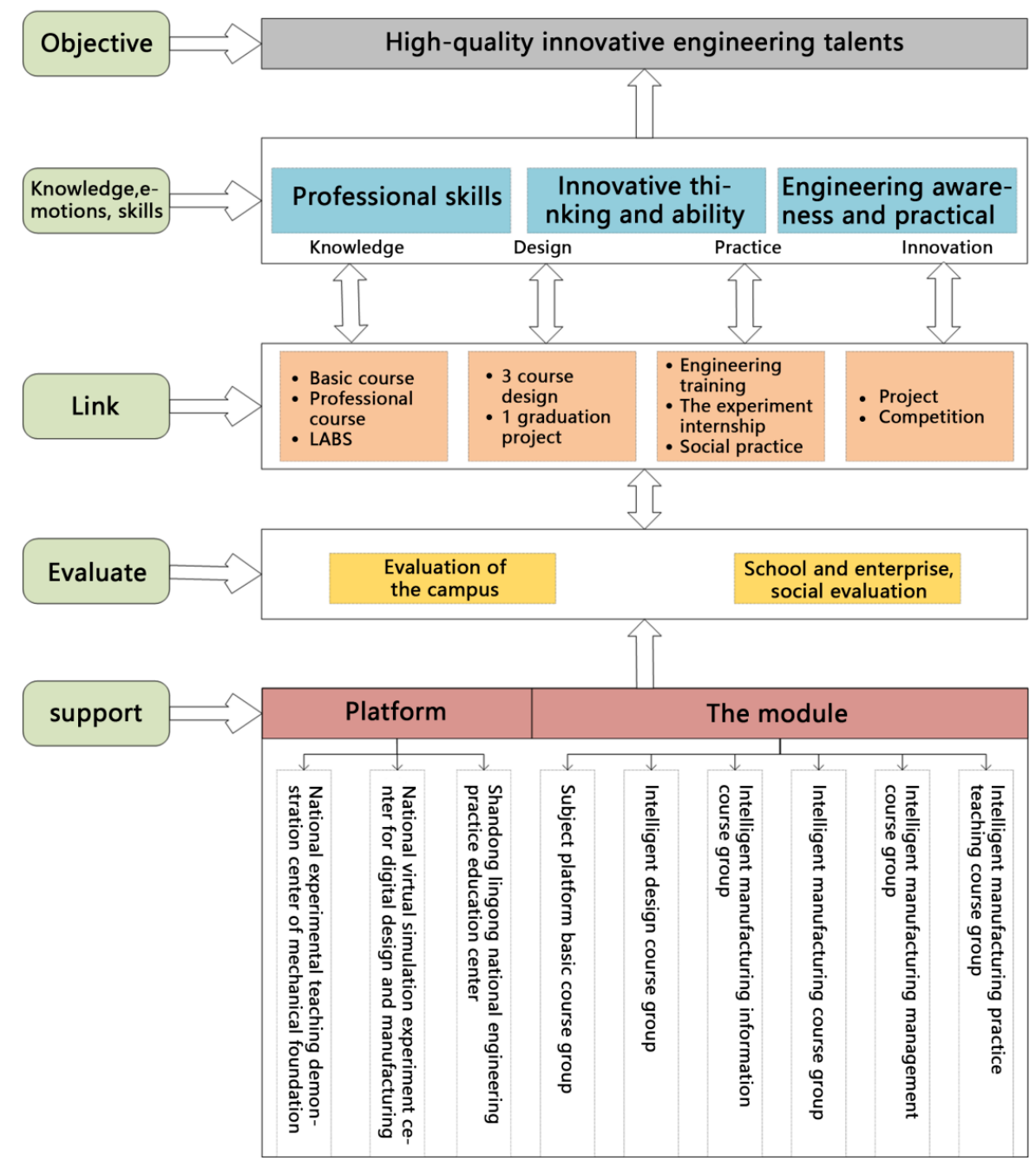

Figure 1. Innovative practice teaching system for new engineering talent training

(2) Establish a new engineering talent innovation practice ability training mode combining teaching, practice and scientific research: design the " $4+5+4$ " practical teaching link mode in the school, and create an off-campus "one-axis double-drive $\mathrm{x}$-item" innovation practice activities.

In view of the gap between the graduates' innovative practice ability and the employer's needs, in order to strengthen the innovative practical ability of new engineering students, make full use of the resources inside and outside the school, organize a variety of extracurricular innovation practice activities, integrate classroom practice and extracurricular innovation activities. To build a long-term and win-win innovative practice teaching platform and design the " $4+5+4$ " practical teaching link in the school:

4 experiments: intelligent equipment comprehensive experiment + mechanical engineering basic experiment + innovative design training experiment + innovative comprehensive experiment;

3 Intern +2 training: [Cognitive internship, production internship, graduation internship] + [Engineering training (electronic), engineering training];

4 designs: 3 course designs +1 graduation design.

Create an off-campus "one-axis dual-drive x-item" innovative practice activities (a "coordination innovation axis for production, study and research", innovative practice, social practice, and $\mathrm{x}$ activities):

Innovative practice activities: various innovative designs, summer schools, science and technology competitions, research projects, innovation forums, etc.;

Social practice activities: social research, corporate social practice, entrepreneurial employment planning, etc.

Bring into play the synergy and innovation advantages of "production, study, and research", combine teacher research projects with student competition and graduation design, and promote practical teaching with scientific 
research. Strengthening the construction of off-campus practice platform: aiming at the lack of initiative of enterprises to receive students' internships, closely combining the scientific research advantages of colleges and universities with the development of enterprises, strengthening the collaborative innovation of "production, study and research", establishing school-enterprise research, teaching, production and training ${ }^{[11-12]}$. The integrated and efficient, efficient and win-win offcampus practice base and its long-term operation mechanism form close cooperation between schools and enterprises, share the results of scientific research and personnel training and provide students with a broader platform for innovative practice.

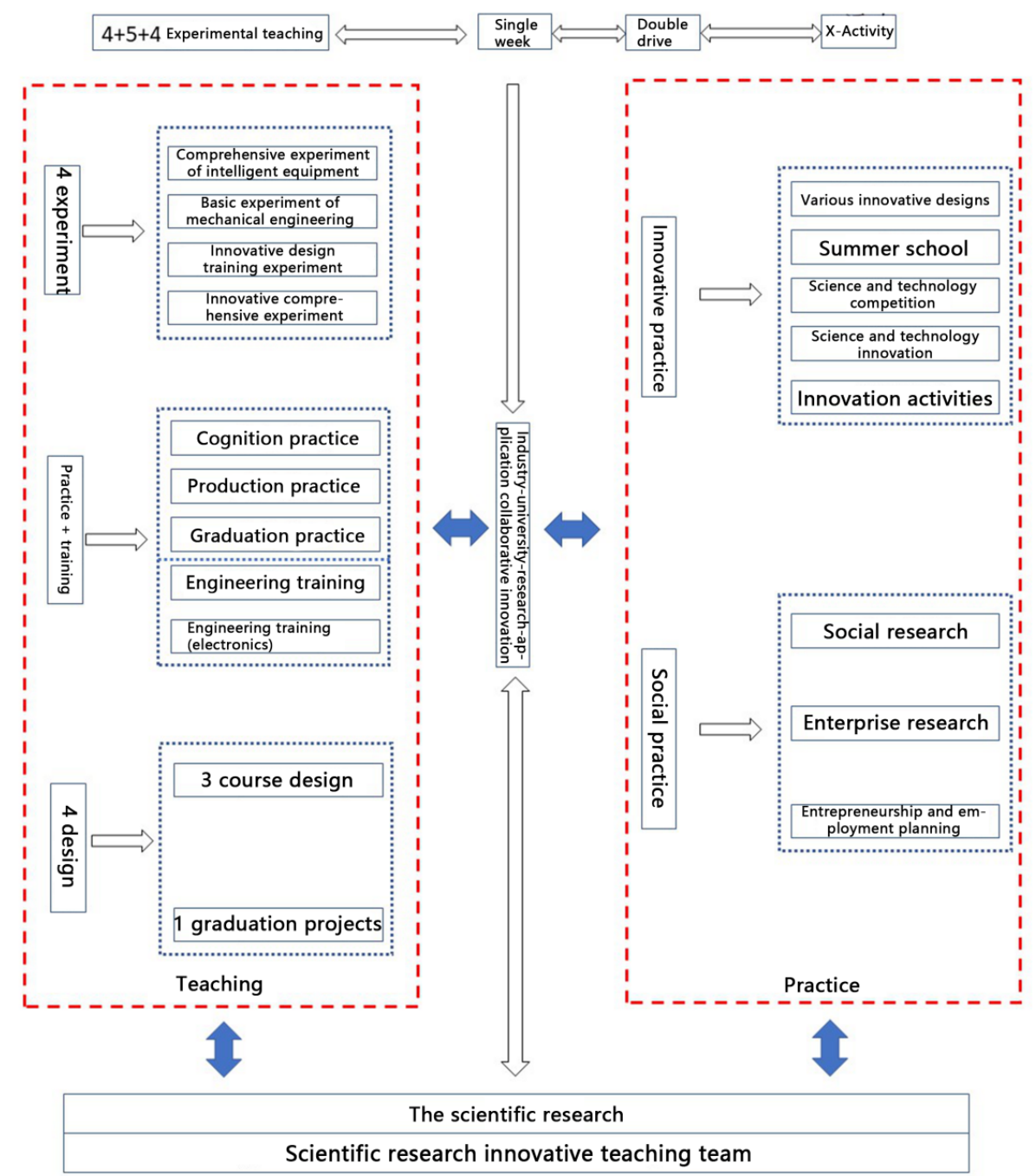

Figure 2. Training mode of new engineering talents innovation practice ability combined with teaching, practice and scientific research

(3) Established a training evaluation mechanism of "innovation drive, teamwork, rolling diversion, and comprehensive evaluation", and introduced team evaluation, training achievements, innovation and entrepreneurship ability, and comprehensive quality assessment into the training of innovative entrepreneurs.

Taking the cultivation of students' innovative practice ability as the goal, taking the principle of effectiveness improvement as the principle, focusing on the process of "focusing on the process and diluting the result", emphasizing the process evaluation, praise and encouragement as the main methods, guiding students to study independently and spontaneously, guiding students to formulate Work plan and work progress, check and urge students to establish research goals in stages, promote implementation in stages, and complete teamwork. Exploring suitable assessment methods and methods for practical teaching activities, focusing on assessing students' innovative thinking ability, practical ability, comprehensive expression ability, knowledge application ability, interpersonal communication ability, teamwork ability, and independent workability ${ }^{[13]}$. Let students enter the role of designers engaged in innovative practice as early as possible, and stimulate students to invest in innovative inventions. Implement a capacity-centered, open-ended assessment 
methodology:

The sense of innovation is quantified ${ }^{[14-16]}$. Students are the main body, set up classroom discussion sessions, mobilize students to think positively, guide students to ask questions, express opinions, express opinions, and use the network platform to carry out interactive communication. The enthusiasm of the students, the depth of the questions and the innovation of the expressions are scored and counted as usual classroom results.

Evaluate team collaboration skills. Combined with professional features, the curriculum design assignments can be theoretical discussion, practical design, etc. Teams are regularly organized to report, based on the team's completion and individual contribution scores, focusing on the team's teamwork ability.

Experimental results highlight practical ability. Establish a variety of evaluation methods such as experimental theory, experimental operation evaluation, experimental report, and results evaluation, and comprehensively evaluate students from the aspects of design thinking, experimental operation ability, comprehensive analysis ability, and the experimental report.

\section{Application}

(1) Reforming the practice teaching system, and constructing a group of "Plant + Module" subject practice teaching courses with distinctive characteristics. The "platform" guarantees the basic quality of talents and the overall requirements for comprehensive development. The "module" realizes the diversion culture of talents from different professions.

The curriculum system covers all aspects, the whole process, and the whole knowledge field. It integrates various technologies and covers various industrial fields such as intelligent manufacturing, information, big data and the Internet of Things, and realizes the stages of design, manufacturing, assembly, management, and maintenance. Digital, informative, and intelligent. The intelligent manufacturing curriculum system forms six-course groups: the subject platform basic course group, the intelligent design course group, the intelligent manufacturing course group, the intelligent manufacturing information course group, the intelligent manufacturing management (decision) course group, and the intelligent manufacturing practice teaching course group. The practical teaching course group consists of four major parts: course teaching, practical teaching, scientific and technological innovation activities, and extracurricular practice activities. The curriculum is designed to run through the innovative practice education model of "knowledge-design-practice-innovation".

The construction of the subjective practice teaching curriculum plays a role in radiation. The achievements of teachers' scientific research have promoted the reform of practical teaching content, the teaching practice of promoting competition in teaching, and the remarkable achievements in the construction of teaching and research projects. Carry out the reform of the practical teaching and training program based on project traction, and advance the graduation design to the sophomore year. Combine with the project teaching method and use the research learning method to learn. The students will be transferred from singularity learning to comprehensive learning to solve practical problems in engineering: based on the principle of "reconstruction of requirements, mastering and mastering the foundation", it is mainly based on guidance, self-study and project research. The excellent rate of classroom evaluation for students in the main courses reaches $100 \%$.

(2) In 2016, Shandong University added "Digital Design and Manufacture National Virtual Simulation Experiment Teaching Center", relying on Shandong University Machinery Foundation National Experimental Teaching Demonstration Center and Shandong University-Shandong Lingong National Engineering Practice Education Center Virtual typical modern manufacturing enterprise environment, with digital design and manufacturing knowledge as the mainline, covering all production links in the production process of the enterprise, building the core of student innovation practice ability training, digital design simulation platform, digital manufacturing simulation platform, digital factory The platform and the innovative practice platform (four platforms) are supported by the virtual simulation experiment teaching system, and strive to improve students' knowledge structure, innovative engineering practice ability and comprehensive quality.

Construction of intelligent manufacturing engineering professional laboratory, set up intelligent design experimental platform, intelligent processing experimental platform, intelligent communicative robot experimental platform, intelligent logistics experimental platform, big data and Internet of Things experimental platform and intelligent management experimental platform and other six experimental platforms.

In recent years, Shandong University has established the Shandong University-Lingong Research Institute and the Shandong University Rizhao Intelligent Manufacturing Research Institute. The school has concentrated its strengths and the equipment manufacturing enterprises in Linyi and Rizhao and launched projects around intelligent equipment and manufacturing. Construction and technology development, intelligent manufacturing and advanced manufacturing common technology have been jointly developed. One of the National Natural Science Foundation Excellent Youth Science Fund 
Project and 164 horizontal projects have been added to jointly carry out personnel training and discipline construction, and the cooperation between the two sides has been pushed to a larger scale. Scope, higher levels, and deeper levels.

(3) The quality of undergraduate talent training continues to improve. In the past three years, students have performed well in various types of innovation competitions. In the "Challenge Cup" national college students' extracurricular academic and scientific works competition, mechanical innovation design competition, mathematical modeling competition, smart car competition, robot competition, etc., undergraduate He has won 28 national first prizes, 19 second prizes, 26 third prizes, 100 provincial first prizes, 67 second prizes and 70 third prizes. For three consecutive years, it has been a hot job profession. The employment demand ratio is over 8:1, and the actual employment rate has been above $95 \%$. In the past three years, there were 688 graduates, and the employment rate of graduates was over $97 \%$, including $97.07 \%$ in $2016,97.19 \%$ in 2017 and $97.39 \%$ in 2018. In this professional direction, the number of employed people accounted for more than $75 \%$, which achieved the goal of professional study and training and realized the education and planning of students in this major.

\section{Acknowledgments}

This work was supported by the fund of education and teaching reform research, Shandong University (2019y100, 2019y112, 2019y113). We especially acknowledge all of the people who have contributed to our research.

\section{Conflict of interest statement}

The authors declare no competing financial interests.

\section{References}

[1] Huai J P. The Exploration and Practice of the Reform on the Cultivationof Top-notch Innovators. Education of Innovative Talents. 2013.

[2] Huang E Q, Gao Y Y. Analysis of teacher's professional quality structure in context of new engineering. Journal of Nanchang Institute of Technology. 2018; 5.

[3] Qiou D, Bai W F. The construction and discussion of the scientific and technological innovation platform of automation specialty based on science and technology competition. Journal of Changchun University of Technology( Higher Education Study Edition). 2011; 3: 24-26.

[4] Chen X Y. Studies on teacher resource's substaintial enhancement in the new undergraduate colleges of Hunan. 2007.

[5] Yang Wei. Cultivation of technological innovation ability in college students on the basis of technology and learning contest. Science-Technology and Management. 2010; 3: 123-126.

[6] Wang R. Relation between Comprehensive Connection Efficiency of Influenced Urban Realm around City Rail Transit Station and Pedestrian-Vehiche Behavior Simulation and the Application of Design. 2017.

[7] Fan L, Ding Z Y. On Construction of Multi disciplinary Competition Platform for Cultivating Practical Innovative Talents. Journal of Southwest China Normal University (Natural Science Edition). 2016; 8.

[8] Huang J D. The Research on College's PBL-based Engineering Talent Cultivation Mechanism. 2008.

[9] Sun W F, Yang J Q. Review of new engineering construction and training of innovative talents. Science \& Technology Vision. 2018; 7.

[10] Luo Z Y, Zhang S T. Exploration on the innovative practice ability training of students in colleges and universities. Experimental Technology and Management. 2009; 7: 35-37.

[11] Jin X Y. Students' science and technology competition with innovative college talent management - A Case of Zhejiang Province. 2013.

[12] Zhang Y. On Construction and Implementation of Extra-curricular Activities System on Science \& Technology in University-empirical study in WUST. 2008.

[13] Ji L D, Zhu J Q. The Summarization of Ten-year Construction of National Experimental Teaching Centers. Research \& Exploration in Laboratory. 2014; 12.

[14] Liu H Y. Study on Sustainable Development Countermeasures of National Demonstration Center for Experimental Economic and Management Education - A Case Study of Jiangxi University of Finance and Economics. 2017.

[15] Zhan D. A. Thesis Submitted in Fulfillment of the Requirements for the Master's Degree of Management. 2008.

[16] Huang S B, Li Y P. Reform of the Pract icing E duc ation System for Engineering Students. Journal of Guilin University of Electronic Technology. 2009; 4: 83-86. 